[RH]Amagnya (Author) Factors Affecting Education in the Builsa District of Northern

Ghana

https://doi.org/10.1080/18146627.2018.1530571

\title{
Factors Affecting Education in the Builsa District of Northern Ghana
}

\author{
Moses Agaawena Amagnya \\ teps://orcid.org/0000-0002-5218-8370 \\ Griffith University, Brisbane \\ moses.amagnya@griffithuni.edu.au
}

\begin{abstract}
Education is important for the successful development and growth of individuals and societies, yet some factors adversely affect its provision. This article reports on a study that explored the factors that adversely affect education in the Builsa District located in the Upper East Region (UER) of Northern Ghana, by examining Chuchuliga people's attitudes and concerns regarding education. Surveys were administered to students, parents/guardians and head teachers, and interviews and focus group discussions were held with opinion leaders and school dropouts, respectively. A striking finding was that the Tono Irrigation Dam located at Navrongo and the predominant economic activity, which is farming, negatively affect education in the community. Further findings were that the late introduction of education in Northern Ghana and traditional beliefs about education, as well as other longestablished factors are responsible for high illiteracy and school-dropout rates. Recommendations to improve the quality of education in the district and country are discussed.
\end{abstract}

Keywords: education; school dropout; poverty; Chuchuliga; Builsa District; Upper East Region, Northern Ghana

\section{Background}

Education significantly influences the socio-economic and political lives of people and is mostly regarded as a key to unlocking the doors of development and escaping poverty (World Bank 2016). For instance, the economic growth and development of countries, such as the United States (US), United Kingdom (UK), Japan and China, are linked to the quality of 
formal education (Thompson 1981). Education provides people with specialised knowledge and skills that create opportunities for massive transformation of their lives and improved standard of living (Peil 1977). It is probably in this light that the United Nations (UN) Declaration of Human Rights (UN 1948) provides that "every child has the right to education at least in the elementary and fundamental stages" and that the aim of the UN Sustainable Development Goal 4 is to "ensure inclusive and equitable quality education and promote lifelong learning opportunities for all” (UN 2015).

Full achievement of educational targets is still problematic notwithstanding numerous educational interventions and initiatives that have made some progress, namely: increased school enrolment and completion rates; reduction in illiteracy rates; and achievement of some amount of gender parity, among others (UNESCO 2012; 2014; UNICEF 2015). Particularly, the UN Millennium Development Goal of achieving universal primary education by 2015 was missed as adult illiteracy and school-dropout rates remain high worldwide, which correlates with low productivity, low incomes and poor health (UNESCO 2011; 2016a). In fact, the high illiteracy and school dropout rates from the 1990s (see UNESCO 1998; UNICEF 1998; World Bank 1991) are still present today. In 2013, for instance, 757 million adults (aged 15 and over) worldwide, were unable to read and write, two thirds of whom were women with one in 10 girls out of school, compared to one in 12 boys (UN 2015). Also, 59 million children of primary school-age were out of school with an estimated one in five of those children dropping out and two in five out-of-school children never setting foot in a classroom (UN 2015). Similarly, in 2014, nearly 61 million primary school-age children and 202 million secondary school-age adolescents were out of school with countries' commitments to halving adult illiteracy levels by 2015 remaining unfulfilled (UNESCO 2016a). Out-of-school rates were higher in rural areas and among children from households headed by someone with less than a primary education, with children from the poorest households almost three times more likely to be out of school than their richer peers (GoG 2012).

Further statistics show that the gap between developed and developing regions stood at nearly 20 per cent: 91 and 72 per cent for developed and developing regions, respectively. For instance, 38 million out of the 58 million primary school-age children who were out of school in 2012 were in Africa, with about half never setting foot in a school in their lifetime (AfricaAmerica Institute 2015). In 2014, there were about 48.7 million illiterate youth and 18.8 
million illiterate adults in sub-Saharan Africa, with between 40 and 90 per cent of children and young people failing to achieve minimum levels of proficiency in reading and/or mathematics (Institute for Statistics 2015; UNESCO 2016a; 2016b). Also, an estimated 40 million Africa youth are projected to drop out of school in the next decade (Africa-America Institute 2015), with Africa facing the greatest challenge of an estimated 24.4 and 44.4 million new primary and secondary school teachers, respectively, needed to fulfil the promise of universal primary and secondary education by 2030. Nearly seven in ten African countries experience acute shortages of trained primary school teachers (UN 2015) with only 71 per cent of teachers in Sub-Saharan Africa and 84 per cent in Northern Africa trained in accordance with national standards (Institute for Statistics 2015). Yet, the rapidly growing populations of African countries (Aitchison and Alidou 2009; Aribisala 2013) make the educational challenges mentioned earlier particularly serious.

Ghana's education system faces several challenges, with illiteracy and school-dropout being the biggest (Aitchison and Alidou 2009; Braimah and Oduro-Ofori 2005; UNICEF 2012). According to the 2000 census, the national illiteracy rate was 46.3 per cent with a rural illiteracy rate of 60.1 per cent, with only one out of eight (12.7\%) people completing primary six (P6); 31.2 per cent and 5.4 per cent completing junior and senior high school, respectively; and 1.3 per cent of people above 15 years having a post senior high education (GSS 2000). In 2009, illiterate adults in Ghana constituted 35 per cent of the adult population (Aitchison and Alidou 2009), with over 20 per cent of school-age children being out of school (GoG 2011). Similarly, about 40 per cent of school-age children were not enrolled in schools in some parts of Northern Ghana (Akyeampong et al. 2007).

Although the Constitution of the Republic of Ghana (GoG 1992) provides for equal and balanced access to basic, secondary and other appropriate pre-university, university and lifelong education, the UER lags in terms of access to and participation in education with high illiteracy and school-dropout rates (MoE 2013). For instance, the UER's school-dropout rate of 2 per cent in 2002 was the highest in the country and the region has consistently recorded least primary school net attendance rate and high numbers of below average students in the Basic Education Certificate Examinations (BECE) (Finger, Lapetina and Pribila 2002; GoG 2012; MEO 2013). The Builsa District of the UER has consistently recorded high illiteracy and school-dropout rates, fewer children in school as well as high numbers of below average students in the BECE over the years (Demographic and Health Survey 2008; GSS 2014; MoE 
2013). According to Amagnya (2005), the lag in education and the high illiteracy and schooldropout rates in Northern Ghana, including the UER is attributable to three factors. First, late introduction of education in Northern Ghana, including the UER, second, colonial administrators prejudice towards natives of Northern Ghana, and third, the deprive nature of the region in terms of natural resources, economic and infrastructural development.

The colonial administration showed prejudice against natives of Northern Ghana in terms of education as they regarded "[t]he people of [Northern Ghana] as amiable but backward people useful as soldiers, policemen and labourers in the mines and cocoa farms [i.e. people] fit only to be heavers of woods and drawers of water for their brothers in the Colony and Ashanti” (Bening 1990, 186). Also, it was very difficult to attract well-qualified and sufficient teachers to Northern Ghana due to long held stereotypes about Northern Ghana and its low economic and infrastructure development (MoE 2013). Regardless of these problems, there is limited research about education in the Builsa District of Northern Ghana with most studies concentrated in Southern Ghana. Currently, there has been no known research conducted in the Builsa District that explored factors affecting education. As noted by Diaz (2007), there are no agreed conclusions on factors that negatively affect education, although parents (family causal factors), teachers (academic causal factors), and students (personal causal factors) are reported in most studies. It was, therefore, important for the current study to explore the factors that affect education in the Builsa District, which may have wider implications for the whole country.

\section{Development of Education in Ghana}

Ghana's education system, which was set up by European merchants and missionaries in the coastal areas and later expanded and scattered over the interior, is modelled on the British system (Graham 1971). Education was introduced in southern Ghana in 1529 and only extended to Northern Ghana in 1908 with four boys from the Northern Protectorate (now Northern, Upper East and Upper West regions) sent to school at Cape Coast (McWilliam and Kwamena-Poh 1975). The first school established in Northern Ghana was at Tamale in 1909 followed by one at Navrongo in 1910, whilst the first in the Builsa District was established by the White Fathers at Wiaga in 1931, but was closed three years later (Bening 1990). At independence in 1957, Ghana had only one university and a handful of secondary and primary schools; but spending on education has increased over the six decades since then, reaching between 30 and 40 per cent of Ghana's annual budget (GoG 2017a). This has 
resulted in an increased number of public and private schools: 19277 kindergartens; 19854 primary schools; 12436 junior high schools (JHS); 828 senior high schools (SHS); 28 training colleges; 20 technical institutions; two polytechnics; 16 universities; and a host of private schools (GoG 2017b).

To make education accessible to all and relevant to the socio-economic, industrial and technological development needs of Ghana, several policy initiatives and changes have been undertaken since independence (Kadingdi 2006). Successive governments have promoted and developed education by providing the necessary infrastructure to train teachers and develop suitable curricula to meet the country's socio-economic and industrial needs. For instance, in the 1980s, the structure of Ghana's education was brought closer to the American model, which was believed to be more responsive to the country's manpower and socioeconomic needs than the more academic British system (Nkongho 2017). The Education Act 1961 (Act 87) (GoG 1961) made access to minimum basic education and functional literacy a fundamental human and birth right of every Ghanaian. The Constitution of the Republic of Ghana (GoG 1992) reiterates education as a basic human right for Ghanaians by providing for the establishment of a free, compulsory universal basic education (FCUBE). FCUBE was actually introduced in 1996 with the aim to provide good quality basic education and to increase access, retention and participation of every child of school-going age in education by improving the quality of teaching and learning; ensuring management efficiency; increasing the enrolment of girls in basic education to equal that of boys; reducing the drop-out rate of girls from 40 per cent to 10 per cent; and ensuring community participation in education (Agbenyega 2007).

A development plan dubbed Ghana "Vision 2020" (The First Step 1996-2000) (GoG 1996) aimed to ensure that all citizens, regardless of gender or social status, would be functionally literate and productive at the minimum. Educational intervention policy initiatives introduced between 2005 and 2016 included a "capitation grant" to absorb school fees at the basic level; "school feeding" to provide free meals to pupils; and "free school uniforms, exercise and textbooks" for vulnerable and poor students in deprived communities. Expenditure on these interventions has increased significantly from GHC9.5 million (US\$2.64 million) in 2005, to GHC88.09 million (US\$24.47 million) in 2011 and GHC168.8 million (US\$46.89 million) in 2016 (GoG 2006; 2017a; 2017b; Otchere-Darko 2011). Also, free education was introduced for Northern Ghana in the 1960s to bridge the educational gap between Northern and 
Southern Ghana (Perbi, Oyangen and Asare-Bediako 2014). These interventions, which aimed to attract and retain children in schools (Agbenyega 2007), resulted in increases in the enrolment rate of school-age children and annual increases in the opening of new schools (GoG 2011). However, simply getting children into schools in today's world is not enough (Boissiere 2004) and governments must ensure that children complete the primary and secondary cycles in order to attain the basic knowledge and skills needed for personal wellbeing and national development.

\section{Factors Affecting Education}

Socio-cultural and economic factors, such as: early marriage; lack of school fees and sponsorship; child labour (engagement of children as house helps or farm workers); quest for wealth, bereavement, truancy, broken homes and poor attitude of parents towards girls' education, have been reported as accounting for low school enrolment and high dropout rates, especially among girls (Okeke, Nzewi and Njoku 2008). Some scholars have found poor academic performance by students, along with issues of administrative discipline, corporal punishment, sexual harassment, child abuse and child labour, as factors that lead to groups of students being excluded from accessing quality education (Glewwe 2002; Kingdon 1996; White 2004). Distance to school also affects school attendance, especially in Africa, as about nine out of every $10(92.1 \%)$ primary school students take about 30 minutes to reach the nearest school, with a figure of 34.8 per cent for SHS students (UNESCO 1991). Finger, Lapetina and Pribila (2002) also found lack of "political will" to tackle problems facing educational systems and non-implementation of good educational policies to be responsible for the poor and low level of education in Ghana; and students' poor performance due to lack of teachers (Bening 1990) usually discourages parents from sending their children to school.

Education in Ghana, particularly the North, has been found to be negatively affected by the Northern Territories non-interest in Western education when it was first introduced; low quality of teachers and frequent transfers; lack of regular inspection by competent educationists; and inadequate equipment and infrastructure (Bening 1990; Oppong 1973). Bradley (2000) found that dire poverty; conflict over limited resources and territorial lines; religious and cultural beliefs; and the late introduction of education in Northern Ghana are factors affecting education. Again, the lack of SHSs in rural areas, which raises the cost of continuing education; cost barriers, the bulk of which comprise rising Parent Teacher Association dues; and the prices of school uniforms, furniture and stationery remain 
significant impediments to accessing primary education, particularly in Northern Ghana, following the abolition of the free education policy in the 1980s (Finger, Lapetina and Pribila 2002; MoE 1997; Wallace-Bruce 2010). Thus, encouraging parents/guardians to pay token fees to enhance quality education (Iddrisu 2001) is making education expensive and out of the reach of the poor.

\section{Methods}

Study Area

The study data was collected at Chuchuliga in the Builsa District, which is located in the UER of Northern Ghana. Builsa District is the largest district in the UER, with land area of 2 $220 \mathrm{~km}^{2}$ constituting 25.1 per cent and a population of 92991 in the 2010 census with a dependency ratio of 51.5:48.5 or 1:0.94 (GSS 2010). It shares boundaries with the KasenaNankana West, Kasena-Nankana East, West Mamprusi, Sisala East, and West Mamprusi districts. The school-age population is about 28311 representing 37.82 per cent of the population with 190 public pre-tertiary educational institutions, seven private schools and a vocational school with educational attainment quite low (Builsa North District Assembly 2014; 2015; Builsa South District Assembly 2014). About two-thirds of the population aged 15 years and above and about half of the population aged six years and above have had no formal education with school attendance among the six to 25 age group lower $(48 \%)$ compared to other districts (54\%) in the region (GSS 2010). Chuchuliga is bordered by Navrongo, China, Sandema and Bui, and has 12 primary schools including Chuchuliga Central, Teidema, Nanjopuing, Naamonsa, among others, and four JHSs - Chuchuliga Central, Teidema, Nanjopuing and Naamonsa (Amagnya 2005). The total number of JHS, SHS and tertiary students in Chuchuliga was 517, comprising 365 JHS, 127 SHS and 25 tertiary students.

\section{Research Design, Sample and Sampling}

The study was conducted using both quantitative and qualitative methods, namely, surveys (with both closed- and open-ended questions), interviews, focus group discussions and observations. The author developed all the research instruments. The research was conducted in accordance with the Kwame Nkrumah University of Science and Technology's ethical code of practice for researchers. Parental approval was sought before involving underage participants in the study where participants' identities were protected, and personalised information was handled with utmost confidentiality. The sample included 150 students from 
ten SHSs, four JHSs and tertiary students who are natives of Chuchuliga (i.e. $75 \mathrm{JHSs}, 52$ SHSs and 23 tertiary students). It comprised 115 (76.67\%) males and 35 (23.33\%) females aged between 14 and 33 years (age: $\mathrm{M}=18.80, \mathrm{SD}=3.53$ ). There were also 10 head teachers ${ }^{1}$ that included eight (80.00\%) males and two (20.00\%) females aged between 25 and 55 years (age: $\mathrm{M}=43.60, \mathrm{SD}=10.30$ ). Although the education gender distribution (i.e. students and head teachers) represents the districts' education gender distribution but not the gender distribution (49.35\% males and 50.65 females) in main the population (GSS 2010). The other samples were 75 parents/guardians, comprising 34 (45.33\%) males and 41 (54.67\%) females aged between 20 and 55 years (age: $\mathrm{M}=42.80, \mathrm{SD}=10.20$ ), five opinion leaders and 20 school dropouts. ${ }^{2}$ Fifty per cent of the surveyed students' parents/guardians and 30 per cent of the surveyed parents/guardians had no formal education at all and 55 and 15 per cent of parents/guardians had a senior high and tertiary education, respectively. Again, 91.33 per cent of the students had four or more siblings and 85.33 per cent of the parents/guardians had more than five children. This large number of siblings and children is a typical condition in Northern Ghana, which is influenced by illiteracy or non-education, children being used as labour on the farms and more children being a source of pride, making some parents desire more children.

\section{Data Collection}

Due to time constraints and bottlenecks, the researcher could not obtain a list of SHSs from the Regional Department of Education, so the researcher randomly selected students from 10 SHSs in the UER and students from all four JHSs in Chuchuliga. Since there were few tertiary students from the village, those who were home for the vacation were contacted for their consent, and all 23 who consented were included in the study. For the JHS students, head teachers of the selected schools were contacted to seek approval to use their schools for the study and they all agreed for their students to participate subject to parental approval. For the SHSs, the head teachers were not contacted as the students were on vacation but parental approval was sought. Two separate list of students, one for all selected JHSs and one for all selected SHSs, were compiled in alphabetical order based on their surnames with each student assigned a serial number on the list. The names of the JHS students were obtained from the schools' attendance registers and the names of the SHS students obtained from the

\footnotetext{
${ }^{1}$ Head teachers refer to the teachers appointed by the Ghana Education Service to lead and oversee the management and administration of the schools.

${ }^{2}$ School dropouts refer to those people who started school and discontinued along the way
} 
Chuchuliga Students Union that had records of all students from the village. A systematic random sampling technique was adopted in which samples from the total population of JHSs and SHSs were drawn after dividing the total number of students by the number of cases required for the sample. This division yielded the sample interval and the first student was selected randomly from the register, and every $n t^{3}$ number on the list was systematically selected thereafter.

The researcher drew a total of 175 students from JHSs, SHSs and tertiary institutions, and thereafter consent forms were given to SHS and JHS students to obtain approval from their parents/guardians while tertiary students provided consent themselves. Three days after giving out the consent forms, the researcher returned to each school to administer the surveys to the JHS students during school hours. The participants were grouped in a separate classroom from other students and the purpose of the study was reiterated before the surveys were administered. The students were supervised by one teacher assigned by the head teachers to monitor the researcher's activities during sampling and administration of surveys. A meeting was scheduled with the SHS and tertiary students at the Chuchuliga JHS premises, five days after consent forms were received. Surveys were distributed to the SHS and tertiary students to be self-completed as they could read and write and returned in a week's time. One hundred and fifty surveys were completed, which indicated a response rate of 85.71 per cent.

The consent forms given to students included a section that invited parents/guardians to participate in the study, so parents/guardians that consented were contacted, and surveys were administered to them. Parents/guardians who had two or more children selected as students counted as one in the parents/guardians' sample. Most of the surveys administered to parents/guardians were explained by the researcher since majority of them could not read and write, but literate parents/guardians self-completed the surveys. Ten head teachers from the four JHSs and six primary schools selected randomly for each of the six zones, formed the head teachers' sample. Surveys were distributed to the head teachers for a week, and there was a 100 per cent response rate. Although there were six zones each with an opinion leader, one opinion leader declined to participate, so five opinion leaders were interviewed one-onone. School dropouts in the community within the past five years at the time, were approached for their consent to participate in the study. All those who consented were put

\footnotetext{
${ }^{3}$ The $n$th term here varies from the third and fifth number in the list across the school categories.
} 
into an alphabetical list and divided into five groups of four for focus group discussions, which were conducted at the Chuchuliga JHS premises. During the data collection, conditions and classroom situations of the schools and other educational issues were also observed. The combination of the various techniques ensured that relevant information and a real picture of the situation on the ground was obtained. Key questions asked in the survey, interviews and focus group discussions included: demographic information (i.e. age, gender, educational background, occupation, number of siblings and children); why the school dropouts and illiteracy in the community; how students attend schools; what reasons account for nonattendance; and what factors adversely affect education.

\section{Data Analysis}

The completed questionnaires were edited, coded and input into the Statistical Package for Social Sciences (SPSS) to generate frequencies, percentages and descriptive statistics, such as means (M) and standard deviations (SD). Responses to the open-ended questions in the survey were also analysed qualitatively. Qualitative data from the interviews and focus group discussions was transcribed and subjected to content analyses to generate relevant themes. Themes from the qualitative data that have similarities with the quantitative data were combined in the findings and discussions, but themes without similarities with the quantitative data were treated separately.

\section{Findings and Discussion}

The study found that there is disparity between girl-and-boy-child education in the district as only 23.33 per cent $(n=35)$ of the students in the study were females. This finding was particularly surprising, considering that there have been numerous educational and sensitisation programmes on girl-child education in Ghana, including the Builsa District in recent times with some parts of the country recording significant improvements (GoG 2012). The full magnitude of this finding is clear when it is compared with gender disparities in education participation in developed countries. For instance, in 1999, Australia recorded a 78.5 per cent apparent retention rate for girls against 66.4 per cent for boys (Collins, Kenway and McLeod 2000). To worsen the situation, it was also found that as students' progress up the educational ladder, the number of female students drastically reduces, which can be attributable to factors like poverty, teenage pregnancy, early marriage, and girls' poor academic performances. For instance, 11.8 per cent of students, 5 per cent of parents/guardians and 20 per cent of head teachers attributed the low level of girl-child 
education to teenage pregnancy with poverty being cited by the majority of the respondents as a major cause. Although this finding is in line with other African studies conducted previously (e.g. Bradley 2000; Wallace-Bruce 2010), it is still surprising as several years have passed with consistent efforts being made to reduce the gender disparity and retain females in schools at all levels.

The study revealed a high dependency ratio as 91.2 per cent and 85 per cent of students and parents/guardians, respectively, reported four or more siblings in their families. Even though this finding is in line with the dependency ratio reported in the 2010 census, the figures in the study were way higher than the census figures. During the interviews, opinion leaders were asked for reasons why the community appears to have this high child per family rate. Attempting to justify the high number of children, they indicated that "children are gifts from God" and normally serve as a "source of labour", especially for farming, hence families try to have as many childeren as they can. The high dependency certainly affects education in the district as parents may be unable to educate the large number of children due to the financial costs associated with educating many children. This is particularly so as the main occupation of the people in the district is subsistence farming $(65 \%$ of surveyed students' parents/guardians and $45 \%$ of surveyed parent/guardians engage in farming) where usually little or nothing is left from farm produce after feeding to sell to support their children's education. Additionally, the large family size makes it very difficult for parents to supervise their children's studies and control their behaviour when they are not in school, especially when more than a quarter of the parents/guardians $(n=23)$ have no education and more than half $(n=41)$ have an education below the tertiary level. Such inability to supervise and control their children's academic work and behaviour often results in poor performance and students sometimes dropping out of school (see Castejon and Perez 1998 in Diaz 2007).

The study found a high school dropout rate in the community as $60,85.33$ and 66.67 per cent of head teachers, students and parents/guardians, respectively, reported students dropping out in their schools and families. When respondents were further asked of what could have accounted for the high dropouts and illiteracy in the community, several factors were expressed with poverty topping in all categories: $88.33,50$ and 33.33 per cent of students, parents/guardians and head teachers, respectively, mentioned poverty as a predominant reason for school dropout. The majority of parents/guardians $(n=64)$ and head teachers $(n=$ 9) complained that cost sharing and full cost recovery at the basic and tertiary levels, 
respectively, made the cost of education very expensive, especially, for poor parents in northern Ghana. This finding aligns with the Centre for the Development of People's (CEDEP 1991) assertion that school dropout rates are higher in rural areas mainly due to fee problems (poverty). Other causes stated by the participants included teenage pregnancy, early marriage, students' indiscipline, inadequate teachers, irresponsible parenting and poor academic performance. Unbelievably, in the 21 st century, the perception of education being a "means to teach the Whiteman's culture to replace the local culture and traditions" was cited as a reason for the high illiteracy rate in the community. Directly linked to school dropout is school non-attendance by school-age children, and so, the study sought to find out why parents/guardians do not or will not send their children to school. A significant number of parents/guardians $(n=56)$ stated that the poor performance of children already sent to school often discouraged them and justified why they do not or will not send their wards to school, as they will also not perform, a probable reason why few students from the district enrol in tertiary institutions.

Farming as the main economic activity in the community and the Tono Irrigation Dam located at Navrongo, which supply water to Chuchuliga community for farming during dryseasons, were found to adversely affect education in the community. Northern Ghana has a prolonged dry season from October to April each year and so irrigation dams such as the Tono Irrigation Dam have been constructed to provide water to communities for farming during the dry season. Thus, it is natural that once parents/guardians engage in dry season farming, in addition to their regular rain season farming, they should be able to raise enough and extra resources to cater for their families including education of their children (Kirchherr and Charles 2016; Tilt, Braun and He 2009; Wang, Lassoie, Dong and Morreale 2013). But instead of contributing positively to education in the community, strikingly, it was revealed that the Tono Irrigation Dam and farming rather appear to adversely affect education in the community on three counts. First, students sometimes miss school so as to accompany their parents to work on the farmlands during rain-season farming or to take animals for grazing. Thus, the students miss the lessons taught on those days, which often results in poor academic performance and school dropout as the students are unable to catch up with their studies.

Second, parents/guardians do not generate enough income from their farming activities to support their children's education and in explaining why their children are not in school or 
dropped out of school, they stated: "Even sometimes the farm produce is not enough to feed the family not alone sell for the payment of school fees." Also, majority $(n=19)$ of school dropouts in the focus group discussions attributed their plight to their parents' inability to pay their school fees because they are farmers. Personally, when I completed JHS, two of my friends with the third and fourth best results (i.e. Basic Education Certificate Examinations) in the school could not continue their education at SHS because their parents could not pay their admission fees. This result appears to resonate with the World Bank's (1995) conclusion that farming communities find it difficult to educate their children to the highest level. Finally, it was found that instead of attending school, students will rather go and work as labourers on the irrigated lands to earn money. This was raised by most head teachers $(n=8)$ and opinion leaders as a significant factor that affects students' school attendance and invariably their performance, which in most cases, may discourage students from continuing with their education.

Other findings included high teacher-student ratio as most of the schools visited had only three teachers who took care of six classes, meaning that each teacher had two classes to handle (each with an average of 75 students). These situations do not give teachers the opportunity to interact properly with students, which makes teaching and learning difficult. Also, the study found that students lacked the necessary learning materials, such as textbooks, uniforms, tables and chairs, especially at the basic level, as the ones provided by the state were inadequate. For instance, over 73 per cent of the students reported not having all the necessary textbooks, which they attributed to failure to pay schools fees and the inadequacy of textbooks in the schools. Similarly, 80 per cent of the parents/guardians indicated that their children did not have the necessary textbooks due to parents' inability to purchase such textbooks. This finding aligns with Boissiere's (2004) assertion that due to budgetary constraints, developing countries have been under-funding textbooks and learning materials for a long time, leading to their relative scarcity. It was also observed that most of the students at the remote schools sit under trees to learn, and when it rains on any particular day, schools are forced to close for the day. In some of the schools visited, even headmasters were found seated under trees to take records of students and do administrative work, which does not promote proper teaching and learning. These findings are critical considering that learning materials and infrastructure are important for effective teaching and learning and have higher impacts in improving primary school outcomes in many developing countries, 
while their non-availability results in low academic performance and high school dropout (Hanushek 1995).

The researcher also observed that the whole district, which is the largest in the UER, had only three SHSs and a technical/vocational school, while Chuchuliga, a community with four JHSs had no SHS to absorb students completing JHS. This observation is particularly important considering that some parents who could not send their children to SHSs indicated that since all the SHSs were outside the town, they could not afford the cost of boarding fees. Thus, some parents do not send their children to school because of the costs of boarding fees. Also, the entire community had and still has no library where students can study when schools close for the day or over weekends and vacations. Notwithstanding all the challenges, school enrolment in the community was found to have increased over a five-year period (20052009) as presented in Table 1. The figures were obtained from the selected schools that had available records and the table was constructed by the researcher. The increase in enrolment is attributed to the educational campaigns that are encouraging parents to educate their children, coupled with the construction of new schools and classrooms in the community within the past five years. Additionally, desks (tables and chairs) have been provided to both primary and JHSs in the community. Also, an ongoing educational campaign on the importance of education in the district through the District Education Directorate is believed to have had a motivational effect on parents who now prioritise the education of their children. The implementation of the capitation grant, school feeding and free school uniforms, text and exercise books are other possible reasons why enrolment in the district is increasing.

Table 1: School enrolment in six selected schools between 2005 and 2009

\begin{tabular}{|l|l|l|l|l|l|}
\hline \multirow{2}{*}{ School } & \multicolumn{5}{l}{ Enrolment by year } \\
\cline { 2 - 6 } & $\mathbf{2 0 0 5}$ & $\mathbf{2 0 0 6}$ & $\mathbf{2 0 0 7}$ & $\mathbf{2 0 0 8}$ & $\mathbf{2 0 0 9}$ \\
\hline Achanyerigoyi Primary & 115 & 132 & 147 & 162 & 180 \\
\hline Awulansa Primary & 108 & 68 & 110 & 123 & 116 \\
\hline Azue-yeri Primary & 213 & 298 & 394 & 425 & 516 \\
\hline Chuchuliga Junior High & 216 & 208 & 173 & 177 & 195 \\
\hline Chuchuliga Primary & 527 & 508 & 521 & 519 & 538 \\
\hline Namonsa Primary & 257 & 255 & 260 & 261 & 288 \\
\hline Total & $\mathbf{1 4 3 6}$ & $\mathbf{1 4 6 9}$ & $\mathbf{1 6 0 5}$ & $\mathbf{1 6 6 7}$ & $\mathbf{1 8 8 3}$ \\
\hline
\end{tabular}




\section{Recommendations and Conclusion}

The study recommends that since the community itself has started constructing a SHS, government should collaborate and support the Chuchuliga SHS Construction Committee to get the school including a library completed within the shortest possible time. Since some parents do not send their children to SHSs which are all outside the town because of the cost of boarding fees, the completion of the SHS may allow such parents to enrol their children in the community SHS as day students, which will reduce the cost significantly. To close the educational gap between girls and boys, the government and the Builsa North and South District Assemblies should design and implement programmes to educate and entice parents to educate the girl-child. Education on birth-control measures encouraging people to give birth to fewer children should be intensified to disabuse the thinking that children are a "source of labour on the farm" and reduce birth rates. Again, vibrant poverty reduction measures or strategies should be implemented in the community to reduce or eradicate poverty. An example is encouraging people to venture into other occupations or providing loan facilities through the Social Investment Fund for people to engage in commercial farming. The government should improve the non-formal education division in the district so that adults who have not had the opportunity to go to school can acquire some level of education to enable them to read and write or at least, speak English.

In conclusion, education is an important aspect of society's survival and progress because it positively impacts on the lives of people and, therefore, everything must be done to ensure that every child, no matter his/her socio-economic status, gets a good education. Yet, various factors affect the development of education in some communities. Some children in Chuchuliga in particular, and the Builsa District in general, do not enjoy education fully as some of them drop out of school. Therefore, the study sought to explore the factors accounting for this and established, among other things, that education in the district and the UER is affected predominantly by poverty; community and parents' attitudes towards education; students' attitudes towards education; and lack of educational infrastructure and learning materials. Importantly, the Tono Irrigation Dam in the region which is supposed to be contributing positively to education is rather negatively affecting education as some students sometimes forgo school to work on the irrigated lands for money. Thus, the study calls for regular studies in the district to assess the progress made in improving the standard and quality of education. 
References

Africa-America Institute. 2015. State of Education in Africa Report 2015: A Report Card on the Progress, Opportunities and Challenges Confronting the African Education Sector. New York: Africa-America Institute.

Agbenyega J. 2007. 'Examining Teachers' Concerns and Attitudes to Inclusive Education in Ghana." International Journal of Whole Schooling 3 (1): 41-56.

Aitchison, J., and H. Aliduo. 2009. The State and Development of Adult Learning and Education in Sub-Saharan Africa: Regional Synthesis Report. Hamburg: UNESCO Institute for Lifelong Learning.

Akyeampong, K., J. Djangmah, A. Oduro, A. Seidu, and F. Hunt. 2007. Access to Basic Education in Ghana: The Evidence and the Issues - Country Analytic Report. Brighton: Consortium for Educational Access, Transitions and Equity.

Amagnya, M. A. 2005. "Factors Affecting Education in the Builsa District of the Upper East Region: A Case Study of Chuchuliga." Undergraduate thesis, Kwame Nkrumah University of Science and Technology, Ghana.

Aribisala, F. 2013. "Population Growth and Control in Africa." Accessed February 22, 2017. https://worldview.stratfor.com/article/population-growth-and-control-africa.

Bening, R. B. 1990. A History of Education in Northern Ghana, 1907-1976. Accra: Ghana Universities Press.

Boissiere, M. X. 2004. "Determinants of Primary Education Outcomes in Developing Countries." Operations Evaluation Department (OED) Working Paper Series. Washington: World Bank.

Bradley, K. 2000. "The Incorporation of Women into Higher Education: Paradoxical Outcomes?" Sociology of Education 73 (1): 1-18. https://doi.org/10.2307/2673196. 
Braimah, I., and E. Oduro-Ofori. 2005. "Basic School Dropout in Ghana: A Case Study of the Amansie West District." Journal of Science and Technology (Ghana) 25 (1): 67-76. https://doi.org/10.4314/just.v25i1.32933.

Builsa North District Assembly. 2014. Composite Budget of the Builsa North District Assembly for the 2014 Fiscal Year. Sandema: Municipal Planning Coordinating Unit.

Builsa North District Assembly. 2015. Implementation of District Medium-Term Development Plan, 2014-2017: Annual Progress Report for 2014. Sandema: District Planning Coordinating Unit.

Builsa South District Assembly. 2014. Draft District Medium Term Development Plan in Line with the Ghana National Medium-Term Development Framework 2014-2017. Fumbisi: District Planning Coordinating Unit.

CEDEP (Centre for the Development of People). 1991. The Impact of NGOs Activities in Ghana. Kumasi: CEDEP.

Collins, C., J. Kenway, and J. McLeod. 2000. Factors Influencing the Educational Performance of Males and Females in School and Their Initial Destinations after Leaving School. Accessed November 22, 2017. http://www.dest.gov.au/NR/rdonlyres/F0270F6EB2C3-4CF4-833D-4C8029EA7D6E/4093/Gender Report.pdf.

Diaz, A. L. 2007. "Personal, Family and Academic Factors Affecting Low Achievement in Secondary School." Electronic Journal of Research in Educational Psychology and Psychopedagogy 1 (1): 43-66.

Finger, B., M. Lapetina, and M. Pribila (eds). 2002. "Intervention Strategies that Work for Youth: Summary of FOCUS on Young Adults End of Program Report." Youth Issues Paper No. 1. Arlington: Family Health International.

Glewwe, P. 2002. "Schools and Skills in Developing Countries: Education Policies and Socioeconomic Outcomes." Journal of Economic Literature 40 (2): 436-482. https://doi.org/10.1257/jel.40.2.436. 
GoG (Government of Ghana). 1961. Education Act 1961 (Act 87). Accra: GoG.

GoG (Government of Ghana). 1992. Constitution of the Republic of Ghana. Accra: GoG.

GoG (Government of Ghana). 1996. Ghana Vision 2020 (The First Step 1996-2000). Accra: GoG.

GoG (Government of Ghana). 2006. "Budget Statement for the Year 2006: Investing in People, Investing in Jobs." Accessed June 27, 2017. http://www.mofep.gov.gh/?q=budgetstatement/2006.

GoG (Government of Ghana). 2011. "Ministry of Education.” Accessed September 12, 2011. http://www.ghana.gov.gh.

GoG (Government of Ghana). 2012. All Children in School by 2015 - Global Initiative on Out-of-School Children - Ghana Country. Accra: UNICEF-Ghana.

GoG (Government of Ghana). 2017a. "Budget Statement and Economic Policy of the GoG for the Financial Year 2017: Sowing the Seeds for Growth and Jobs." Accessed June 27, 2017. http://www.mofep.gov.gh/?q=content/2017-budget-statement-and-economic-policy.

GoG (Government of Ghana). 2017b. "Schools and Universities.” Accessed May 12, 2017. http://www.ghana.gov.gh.

Graham, C. K. 1971. The History of Education in Ghana. London: Frank Cass.

GSS (Ghana Statistical Service). 2000. 2000 Population and Housing Census. Accra: GSS.

GSS (Ghana Statistical Service). 2010. 2010 Population and Housing Census. Accra: GSS.

GSS (Ghana Statistical Service). 2014. Ghana - Demographic and Health Survey 2014. Accra: GSS 
Hanushek, E. 1995. "Interpreting Recent Research on Schooling in Developing Countries." World Bank Research Observer 10 (2): 227-246. https://doi.org/10.1093/wbro/10.2.227.

Iddrisu, S. 2001. Communities Urged to Support Education. Accra: Daily Graphic.

Institute for Statistics. 2015. Adult and Youth Literacy: UIS Fact Sheet 2015 No. 32. Paris: UNESCO.

Kadingdi, S. 2006. "Policy Initiatives for Change and Innovation in Basic Education Programmes in Ghana." Educate 4 (2): 3-18.

Kingdon, G. 1996. "The Quality and Efficiency of Private and Public Education: A Case Study of Urban India." Oxford Bulletin of Economic Statistics 58 (1): 57-82. https://doi.org/10.1111/j.1468-0084.1996.mp58001004.x.

Kirchherr, J., and K. J. Charles. 2016. "The Social Impacts of Dams: A New Framework for Scholarly Analysis.” Environmental Impact Assessment Review 60: 99-114.

McWilliam, H. O. A., and M. A. Kwamena-Poh. 1975. The Development of Education in Ghana: An Outline. London: Longman.

MoE (Ministry of Education). 1997. Causes of Dropout from Basic Education in Ghana. Accra: Ghana Publishing.

MoE (Ministry of Education). 2013. Education Sector Performance Report, 2013. Accra: Ghana Publishing.

Nkongho, A. A-N. 2017. "Risks and Uncertainties in Vocational Education in Africa." In Risk, Education and Culture, edited by A. Hope and P. Oliver. London: Routledge.

Okeke, E. A. C., U. M. Nzewi, and Z. Njoku. 2008. Tracking School Age Children's Education Status in UNICEF A-Field States. Enugu: UNICEF.

Oppong, C. 1973. Growing Up in Dagbon. Tema: Ghana Publishing. 
Atchere-Darko, G. 2011. “Government's Decision to Cut Spending on Capitation Grant and Other Social Interventions Hurting Education." Accessed September 12, 2011. https://www.modernghana.com/news/.

Peil, M. 1977. Consensus and Conflict in African Societies: An Introduction to Sociology. Harlow: Longman.

Perbi, A. A., K. Oyangen, and E. Asare-Bediako. 2014. "The Growth and Development of Free Education in Northern Ghana: 1951-1966.” MPhil dissertation, University of Ghana.

Thompson, A. R. 1981. Education and Development in Africa. New York: St. Martin's Press.

Tilt, B., Y. Braun, and D. He. 2009. "Social Impacts of Large Dam Projects: A Comparison of International Case Studies and Implications for Best Practice." Journal of Environmental Management 90 (3): 249-257. https://doi.org/10.1016/j.jenvman.2008.07.030.

UN (United Nations). 1948. "Universal Declaration of Human Rights.” Accessed November 22, 2017. http://legal.un.org/avl/ha/udhr/udhr.html.

UN (United Nations). 2015. "Sustainable Development Goals." Accessed June 27, 2017. https://sustainabledevelopment.un.org.

UNESCO (United Nations Educational, Scientific and Cultural Organisation). 1991. World Education Report 1991. Paris: UNESCO.

UNESCO (United Nations Educational, Scientific and Cultural Organisation). 1998. World Education Report 1998: Teachers and Teaching in a Changing World. Paris: UNESCO.

UNESCO (United Nations Educational, Scientific and Cultural Organisation). 2011. Education for All (EFA) Global Monitoring Report 2011: Regional Overview: Sub-Saharan Africa. Paris: UNESCO. 
UNESCO (United Nations Educational, Scientific and Cultural Organisation). 2012. Global Initiative on Out-of-School Children: Ghana Country Study. Paris: UNESCO.

UNESCO (United Nations Educational, Scientific and Cultural Organisation). 2014. Education for All (EFA) 2015 National Review Report: Ghana. Paris: UNESCO.

UNESCO (United Nations Educational, Scientific and Cultural Organisation). 2016a. Global Education Monitoring Report 2016: Education for People and Planet: Creating Sustainable Futures for All. Paris: UNESCO.

UNESCO (United Nations Educational, Scientific and Cultural Organisation). 2016b. Global Education Monitoring Report 2016: Gender Review: Creating Sustainable Futures for All. Paris: UNESCO.

UNICEF (United Nations Children's Fund). 1998. The State of the World's Children 1998: Education: Focus on Nutrition. Oxford: Oxford University Press.

UNICEF (United Nations Children's Fund). 2012. The State of the World's Children 2012: Children in an Urban World. New York: UNICEF.

UNICEF (United Nations Children's Fund). 2015. Out-of-School Children. New York: UNICEF.

Wallace-Bruce, N. L. A. 2010. "Assessment of Factors Affecting Female Participation in Senior High School Education in Ghana: A Case Study of the Asunafo North and Sunyani Municipalities and Kumasi Metropolitan Area." MSc dissertation, Kwame Nkrumah University of Science and Technology.

Wang, P., J. P. Lassoie, S. Dong, and S. J. Morreale. 2013. “A Framework for Social Impact Analysis of Large Dams: A Case Study of Cascading Dams on the Upper-Mekong River, China." Journal of Environmental Management 117: 131-140. https://doi.org/10.1016/j.jenvman.2012.12.045. 
White, H. 2004. Books, Buildings, and Learning Outcomes: An Impact Evaluation of World Bank Support to Basic Education in Ghana. Washington: World Bank. https://doi.org/10.1596/0-8213-5884-7.

World Bank. 1991. World Development Report 1991: The Challenge of Development. New York: Oxford University Press

World Bank. 1995. World Development Report 1995: Workers in an Integrating World. New York: Oxford University Press.

World Bank Group. 2016. Results in Education for All Children (REACH): Assessment of the Pilot Year. Washington: World Bank. 